\title{
Editorial
}

\section{Recent Progress in Differential and Difference Equations}

\author{
J. Diblík, ${ }^{1,2}$ E. Braverman, ${ }^{3}$ Yu. Rogovchenko, ${ }^{4}$ and M. Růžičková ${ }^{5}$ \\ ${ }^{1}$ Department of Mathematics and Descriptive Geometry, Faculty of Civil Engineering, \\ Brno University of Technology, Veveř́ 331/95, 60200 Brno, Czech Republic \\ ${ }^{2}$ Department of Mathematics, Faculty of Electrical Engineering and Communication, \\ Brno University of Technology, Technická 10, 61600 Brno, Czech Republic \\ ${ }^{3}$ Department of Mathematics and Statistics, University of Calgary, 2500 University Drive N.W., \\ Calgary, Alberta, Canada T2N1N4 \\ ${ }^{4}$ Department of Mathematics and Mathematical Statistics, Umea University, \\ SE-901 87 Umeå, Sweden \\ ${ }^{5}$ Department of Mathematics, Žilina University, Universitná 8215/1, \\ 01026 Žilina, Slovakia
}

Correspondence should be addressed to J. Diblík, diblik@feec.vutbr.cz

Received 4 September 2011; Accepted 4 September 2011

Copyright (C 2011 J. Diblík et al. This is an open access article distributed under the Creative Commons Attribution License, which permits unrestricted use, distribution, and reproduction in any medium, provided the original work is properly cited.

This special issue on Recent Progress in Differential and Difference Equations contains fortyfour research articles. Most papers originate from the talks at the Conference on Differential and Difference Equations and Applications (where all Guest Editors served as organizers) held in Rajecké Teplice, Slovak Republic, during June 21-25, 2010 (http://fpv.uniza.sk/ cddea2010/page.php?id=19\&action=show). At the conference, more than 50 contributed papers and posters were presented along with eighteen invited lectures delivered by leading researchers such as Professors A. A. Boichuk (Slovak Republic), T. A. Burton (USA), V. Covachev (Oman), O. Došlý (Czech Republic), J. Džurina (Slovak Republic), J. Jaroš (Slovak Republic), D. Khusainov (Ukraine), W. Kratz (Germany), N. Partsvania (Georgia), I. Rachůnková (Czech Republic), V. Răsvan (Romania), M. Rontó (Hungary), S. Staněk (Czech Republic), M. Tvrdý (Czech Republic), and F. Sadyrbaev (Latvia). In addition to the papers discussed at the conference, many articles have been written for publication in this issue. As a result, seventy-seven authors from sixteen countries contributed to the success of this thematic collection of papers.

The issue covers a wide variety of problems for different classes of ordinary, functional, impulsive, stochastic, fractional, partial differential equations, as well as difference and integrodifferential equations, inclusions, and dynamic equations on time scales. The topics 
discussed in the contributed papers are traditional for qualitative theory of differential, functional differential, difference, and other classes of equations. The issue contains papers on asymptotic behavior of positive solutions of functional differential equations of delayed type, solutions to third-order trinomial delay differential equations, half-linear $q$-difference equations, solutions to discrete equations with two delays in the critical case, solutions to delay difference and integrodifferential equations, as well as research on weighted asymptotically periodic solutions to linear Volterra difference equations. Furthermore, asymptotic properties of third-order nonlinear functional differential equations with mixed arguments and variational equations are investigated.

Traditionally, stability problems receive a great deal of attention at various conferences. Papers included in this issue address stability of linear differential equations with several delays, stability of linear delay differential equations under Perron's condition, exponential stability of solutions to stochastic control systems with delay, and instability of the trivial solution of autonomous differential systems with quadratic right-hand sides in a cone.

As usual, many papers deal with oscillation and nonoscillation of various classes of equations. In particular, a number of papers are concerned with oscillation of secondorder neutral delay dynamic equations of Emden-Fowler type, second-order neutral functional differential equations with mixed nonlinearities and of mixed type, second-order superlinear neutral differential equations, singular nonlinear differential equations, secondorder sublinear impulsive differential equations, and half-linear differential equations. In addition, nonoscillation of advanced differential equations with several terms, second-order dynamic equations with several delays, and first-order neutral differential equations are studied.

Several authors deal with different aspects of the theory of boundary value problems for nonlinear fractional differential equations, $q$-difference inclusions, and weakly nonlinear delay differential systems. Interesting results are obtained for a class of fourth-order boundary value problems, singular boundary value problems for nonlinear fractional differential equations, nonseparated three-point boundary value problems for linear functional differential equations, and periodic problems for difference equations.

Papers collected in this special issue are also concerned with a maximal number of period annuli, Lie groups in infinite dimension, Weyl-Titchmarsh theory for time-scale symplectic systems on a half line, compatible and incompatible nonuniqueness conditions for the classical Cauchy problem, optimization of solutions to dynamic systems with random structure, application of discrete Mittag-Leffler functions in linear fractional difference equations, conjugacy of self-adjoint even order difference equations, $H_{\infty}$ estimates for Lipschitz nonlinear discrete-time systems with delay, and reducibility of quasiperiodic Hamiltonian systems with a small perturbation. Existence of invariant sets for impulsive differential equations with particularities in $\omega$-limit set and existence of pseudosymmetric solutions to $p$-Laplacian differential equations involving derivative are explored.

Finally, some applied problems are also considered-a two-species cooperative Lotka-Volterra system of degenerate parabolic equations, equations of Emden-Fowler type, and oscillatory periodic solutions for two differential-difference equations that model phaselocked loop control of high-frequency generators and nonlinear growth of a fluctuating population.

Although it is not possible to adequately represent in this special issue all directions of current research in ordinary, functional, partial, impulsive, dynamic, stochastic differential equations, difference, and integrodifferential equations, we believe that it reflects many 
important recent trends in research, indicates current challenging problems, and outlines new ideas for future studies in the field.

J. Diblík

E. Braverman

Yu. Rogovchenko

M. Růžičková 


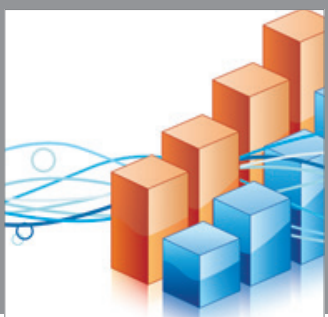

Advances in

Operations Research

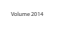

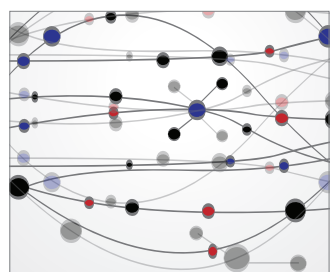

\section{The Scientific} World Journal
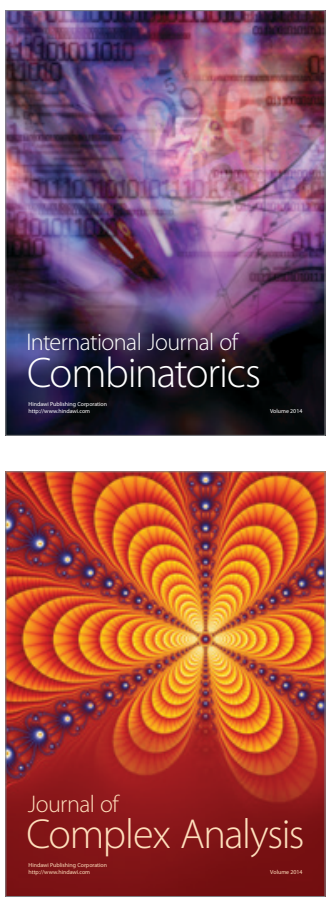

International Journal of

Mathematics and

Mathematical

Sciences
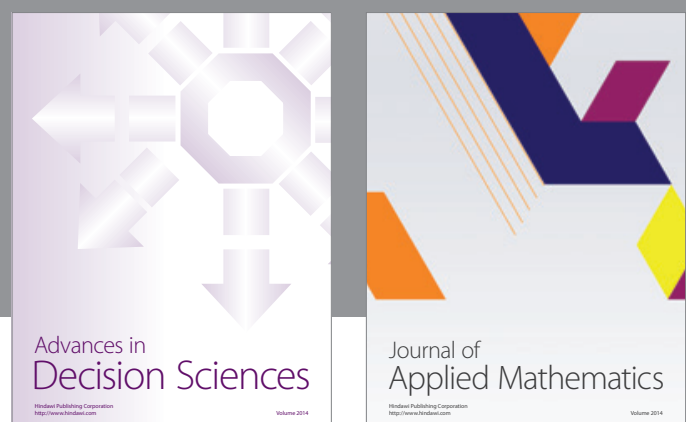

Journal of

Applied Mathematics
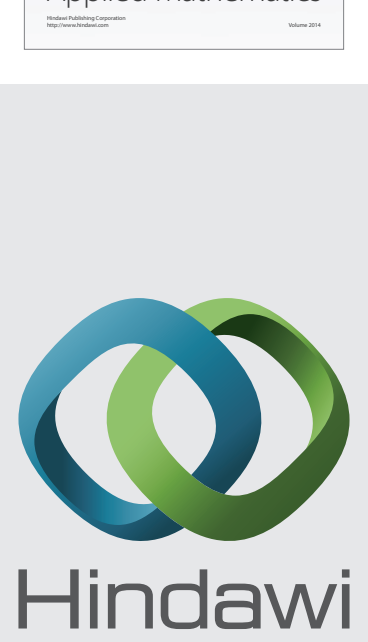

Submit your manuscripts at http://www.hindawi.com
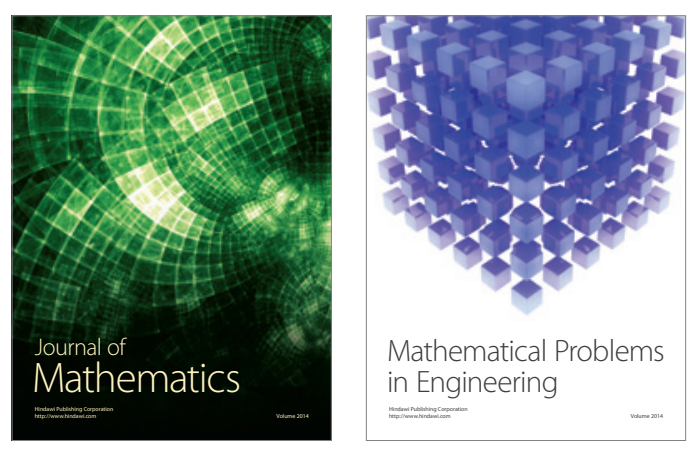

Mathematical Problems in Engineering
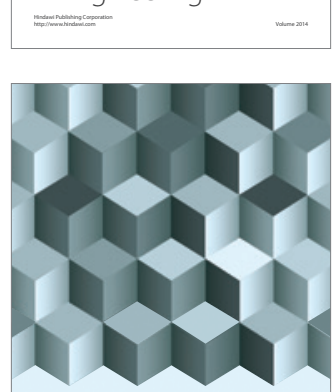

Journal of

Function Spaces
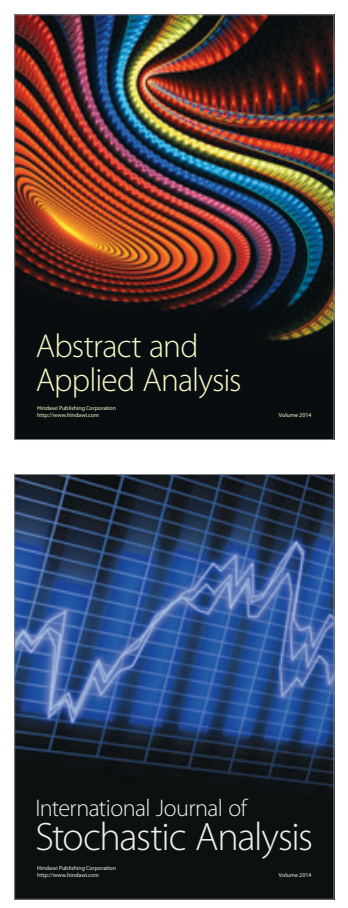

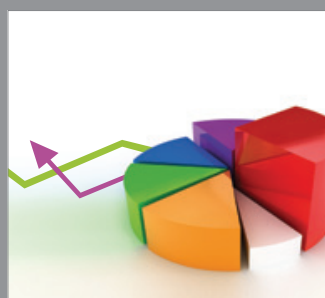

ournal of

Probability and Statistics

Promensencen
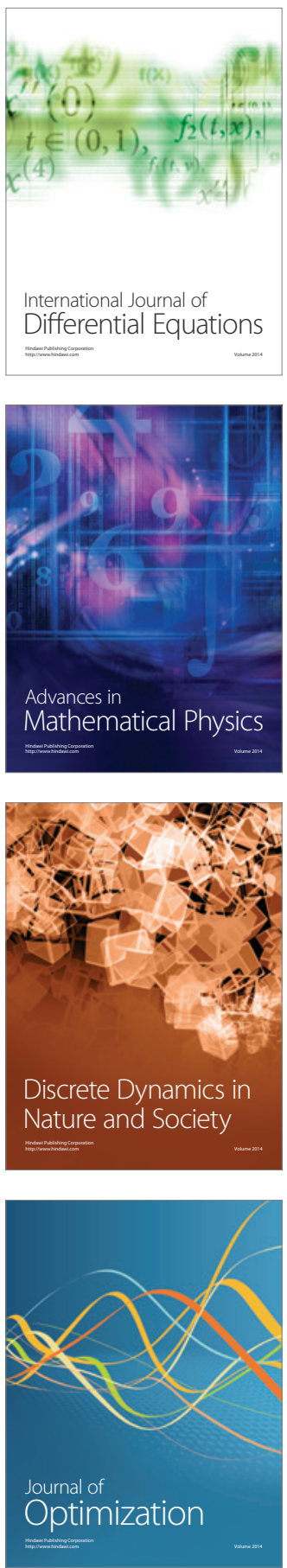